\title{
ENTRE LA RIQUEZA Y LA EXTRAVAGANCIA: EL CONSUMO EXCÉNTRICO DEL NARCOTRAFICANTE EN MÉXICO.
}

\author{
Between wealth and extravagance: The eccentric consumption of the drug \\ trafficker in Mexico / Entre a riqueza e à extravagância: o consumo excêntrico do \\ narcotraficante no México
}

Juan Antonio Fernández Velázquez ${ }^{1}$ y Héctor Manuel Pimienta Fernández ${ }^{2}$

\section{RESUMO}

O presente texto apresenta os resultados de um estudo realizado com base em revisões documentais, cujo objectivo consiste em apresentar reflexões centradas nas abordagens de autores como Bordieu (1979) e Veblen (1944), entre outros, que permitiu analiasar as diferentes práticas de consumo material e simbólico, relativamente ao caso do narcotraficante no México, que transitou do sumptuário para o excêntrico, durante a maior parte da segunda metade do século XX. Isso tem implicações simbólicas que se reflectem tanto no poder económico dessas personagens, através dos bens adquiridos, como nas suas formas de se vestirem, deste modo, nesse cenário cria-se uma imagen, em torno de ser um traficante de drogas que, a princípio, estava ligado ao meio rural, sendo que, com o passar dos anos, tornou-se mais urbanizado. Essa imagen também implica a expressão de um status dentro das organizações criminosas, que funciona como um elemento de distinção entre os seus membros.

Palavras-chave: Consumo de Materiais, Distinção, Excentricidade, Traficante de Drogas.

Recebido: Fevereiro 2018

Aceitado: Junho 2018

\section{RESUMEN}

El presente texto tiene como propósito realizar un estudio en base a una revisión documental, a partir del planteamiento de autores como Bordieu (1979) y Veblen (1944) entre otros, que nos permita abordar las diferentes prácticas de consumo material y simbólico esto para analizar el caso del traficante de drogas en México, mismas que transitan de lo suntuario a lo excéntrico durante buena parte de la segunda mitad del siglo XX. Esto tiene implicaciones simbólicas que se reflejan en el poder económico de dichos personajes a través de los bienes adquiridos, así

\footnotetext{
${ }^{1}$ Doctor en Historia y Estudios Regionales; Profesor Investigador adscrito a la Dirección de Investigación y Posgrado de la Universidad Autónoma Intercultural de Sinaloa, campus Mochis; miembro de la Red de Investigadores Latinoamericanos por la Democracia y la Paz, donde se desempeña como director de Investigación, Mexico. Correo electrónico: jantoniofernandezv@gmail.com

${ }^{2}$ Licenciado en Sociología por la Facultad de Ciencias Sociales campus Mazatlán y Maestro en Historia por la Facultad de Historia, Universidad Autonoma de Sinaloa. Mexico.
} 
como de su vestimenta, en este escenario se crea una imagen en torno al ser narcotraficante que en un principio estuvo ligado al entorno rural que conforme pasaron los años se fue haciendo más urbanizado. Esta imagen también implica la expresión de un estatus dentro de las organizaciones delictivas que funciona como elemento de distinción entre sus miembros.

Palabras clave: consumo material, distinción, excentricismo, narcotraficante.

\section{ABSTRACT}

The present text aims to conduct a study based on a documentary review, based on the approach of authors such as Bordieu (1979) and Veblen (1944), among others, which allows us to address the different practices of material and symbolic consumption to analyze the case of the drug trafficker in Mexico, who transited from the sumptuary to the eccentric during much of the second half of the twentieth century. This has symbolic implications that are reflected in the economic power of these characters through the acquired goods, as well as their clothing, in this scenario an image is created around being a drug trafficker that at first was linked to the rural environment that as the years passed, it became more urbanized. This image also implies the expression of a status within criminal organizations that functions as an element of distinction among its members

Keywords: material consumption, distinction, Eccentricism, drug dealer.

\section{INTRODUCCIÓN}

Algunos actores sociales han sabido construir cuantiosas fortunas al margen de la legalidad institucional mediante la práctica de acciones ilícitas que les han permitido generar rápida o paulatinamente, múltiples ganancias, es el caso de los narcotraficantes. Sin embargo, en particular escenario son también pocos los que han ostentado un poder y una riqueza debido a su posición dentro de las organizaciones dedicadas al tráfico de enervantes.

Para algunos de los capos del narcotráfico mexicano -fallecidos, capturados o prófugos de la justicia- en la medida en que sus fortunas se incrementaron debido al tráfico de drogas, principalmente hacia el mercado norteamericano, y además de lo generado por la práctica del lavado de dinero en América Latina y Norteamérica, el derroche de las opulentas ganancias de estas 
Entre la riqueza y la extravagancia: El consumo excéntrico del narcotraficante en M éxico.

actividades se ha expresado bienes materiales que ellos poseen y las formas de consumo practicadas tanto en ellos.

La ostentosidad del lujo y lo extravagante o fuera de lo normal - de acuerdo como lo marcan algunas referencias denominativas de lo excéntrico- de estos personajes mexicanos de las cúpulas del poder económico de las drogas del ayer y hoy, han mostrado sus particularidades de consumo material y cultural, en el plano de lo simbólico, a través de distintas maneras tanto en vida como en el lecho de muerte. Las cuales se encuentran entre formas expresivas diversas, algunas homogéneas, así como también peculiares. En ese sentido, la posición dentro de las redes del narcotráfico se ha visto reflejada en las propias prácticas y los bienes materiales adquiridos a lo largo del tiempo.

Abordar las prácticas de consumo de estos personajes también explica el sistema social en el cual están inmersos, los valores y cambios simbólicos que se le otorgan a ciertos objetos materiales y el uso de los mismos en una sociedad que directa e indirectamente acepta y mitifica, pero a su vez condena y rechaza el actuar de estos capos. A través de autores como Lipovetsky, Gilles, Roux Elyette, (2004); Bourdieu (1979) retomamos algunos elementos interpretativos sobre el lujo, el consumo y la distinción en sus significados en el mundo social contemporáneo. Este estudio alude principalmente al consumo material de los narcotraficantes de las postrimerías del siglo $X X$ y de los años actuales, estos vinculados con la zona del pacífico mexicano, particularmente el noroeste.

\section{APROXIMACIONES CONCEPTUALES AL CONSUMO MATERIAL}

Cuando hablamos del consumo realizado por los traficantes de drogas nos trasladamos al mundo del lujo material ya sea considerado excéntrico, extravagante $o$ atípico para una sociedad determinada. El lujo como fenómeno de estudio, de acuerdo con Lipovetsky lleva a complejizar más la comprensión de las prácticas adquisitivas de bienes materiales debido a su inmersión en el plano de lo simbólico y su relación con las mentalidades y las actitudes vinculadas al lujo en las diversas civilizaciones en el presente y el pasado (Lipovetsky y Roux, 2004: 18). 
En ese sentido, el lujo tiene su propia historia y en añadidura sus marcadas diversificaciones y transformaciones a lo largo del tiempo.

El lujo ha atravesado un proceso histórico a lo largo de las sociedades existentes, para el autor pudiésemos hablar de un antes y un después a raíz de la aparición del Estado y las sociedades divididas y/o jerarquizadas. Es decir, cuando se estableció una separación de los grupos en clases y cuando el "lujo ya no coincidió exclusivamente con los fenómenos de circulación-distribución-desatesoramiento de las riquezas, sino también con nuevas lógicas de acumulación, centralización y de jerarquización" (Lipovetsky, Gilles, Roux Elyette. 2004). Por lo que, siguiendo con el planteamiento del devenir histórico del lujo expuesto por el autor;

En las sociedades jerarquizadas, la vida entera se estructura en torno a la escisión ostensible entre bienes opulentos y bienes ordinarios. Esplendor de unos, indigencia de la mayoría, por doquier las sociedades estatalesjerárquicas conllevan la desigualdad de las riquezas, la división social entre las maneras de poseer y de gastar, de alojarse y de vestir, de alimentarse y de divertirse, de vivir y de morir (Lipovetsky, Gilles, Roux Elyette 2004: 30).

El pasado siglo XX se caracterizó por la denominada sociedad de consumo, misma que tuvo como hechos históricos fundamentales para su existencia al Fordismo y al llamado Taylorismo. Los cuales se convirtieron -como resultados de la Revolución Industrial- en los procesos génesis para la elaboración en masa, el crecimiento y el desarrollo de la producción-venta-adquisición de bienes materiales en un mundo que "no necesitaba a la gente, salvo consumidores" (Hobsbawm, 2004: 269). Bajo dicha idea, fue en la vigésima centuria y lo que va del presente siglo donde el consumo de mercancías ha sido una característica central de nuestra sociedad contemporánea (Wünderich, 2002: 235).

El poder adquisitivo de un individuo y el gusto puede marcar la diferencia al momento del consumo de un bien (producto/mercancía), último que se encuentra entre el plano del valor económico y el simbólico, ambos culturalmente conformados. Así, son distintos los tipos de consumo que se ponen en práctica. Uno de ellos es el que remite a la ostentosidad del lujo y lo excéntrico, es decir, el suntuario, este último ya sea de bienes catalogados como antiguos o de los 
Entre la riqueza y la extravagancia: El consumo excéntrico del narcotraficante en M éxico.

considerados modernos. Al respecto, Throstein Veblen hacia 1899 planteó que "para ganar y conservar la estima de los hombres no basta con poseer riqueza y poder... [...] tienen que ser puestos de manifiesto, porque la estima sólo se otorga ante su evidencia" (Veblen, 1944: 44).

Ostentar un lujo, sea excéntrico o no, ha sido una práctica comúnmente relacionada con una clase social a lo largo del tiempo, misma que por lo general ha contado con una acumulación de capital superior a la del común de los miembros de un grupo o sociedad determinada. Al respecto, de acuerdo con el intelectual francés Pierre Bourdieu, "la clase social no se define sólo por una posición en las relaciones de producción, sino también por el habitus de clase que "normalmente"... [...] se encuentra asociado a esta posición" (Bourdieu, 1979: 349). Es decir, la clase social no sólo se define por el lugar ocupado dentro de la estructura económico-social, sino por las prácticas socioculturales presentes en los grupos, para el caso que hacemos alusión las adquisitivas de índole material. Por lo que "disponer de bienes de consumo de simbolismo realzado, expresa por un lado la necesidad de diferenciación y delimitación social, y por el otro, la apropiación activa de los hábitos de consumo de las clases privilegiadas" (Jaramillo, 1996: 49-50). Desde una posible interpretación postfuncionalista, esto se traduce en que;

Un bien proporciona al consumidor una utilidad intrínseca, ligada al nivel absoluto del consumo, pero también le proporciona estatus. Este último está ligado a su consumo en relación con el consumo de los otros agentes. [...] Los bienes que son demandados principalmente por su capacidad de generación de estatus se denominan ostentosos o de lujo (Wünderich, 2002: 236).

No alejada del planteamiento anterior se encuentra la reflexión del sociólogo alemán Georg Simmel, quien señala que el consumo puede ser entendido como una forma de identificación personal y colectiva donde se revela la fuerza de las orientaciones de la identidad de los sujetos así como su personalidad, ello en el sentido de que existe cierta tendencia a la individualización y a la diferenciación determinada por las circunstancias personales, históricas y sociales con relación a la comunidad a la que se pertenece (Simmel, 1986: 749). 
En la época contemporánea el lujo se ha personalizado y la riqueza del material con que están hechos los productos ya no sólo les da a estos dicho estatus en el mercado ya sea local o internacional, sino que entran en juego otras fuerzas como el prestigio y las marcas, elementos en sí que están más dentro del plano de lo simbólico. No obstante, "desde los años ochenta, las nuevas élites del mundo económico exhiben sin complejos su gusto por los productos de lujo y los símbolos de estatus social" (Lipovetsky y Roux, 2004: 57).

Autores como el propio Lipovetsky han señalado que la idea del estatus social no puede llegar a ser la única vía de explicación del consumo suntuario o de lujo, sino que en el mundo contemporáneo el individualismo ha trastocado incluso las formas de adquisición y las significaciones intrínsecas en dichas prácticas. Recogiendo su reflexión, -sin buscarle una analogía directa al narco-consumo aunque pudiese parecerlo- el autor establece que "el consumidor de lujo idealtípico es en lo sucesivo multifacético, toma prestados sus modelos de diversos grupos, mezcla distintas categorías de objetos de diferentes precios y de diferentes estilos. La movilidad, la hibridación y el disparate han tomado el relevo del lujo afectado <<commeilfaut>>" (Lipovetsky, Gilles, Roux Elyette, 2004). Y cada vez más el lujo tiende a representarse en el individuo privado y/o en lo íntimo, es decir, la idea del lujo para sí sin fines demostrativos hacia el exterior como característica primordial (Lipovetsky y Roux 2004: 62).

Retomando la idea anterior, vemos cómo el lujo y las prácticas de consumo sobre este no son iguales todos los tiempos, los cambios ocurridos en estas son parte de los procesos vividos en las diversas sociedades del orbe y las lógicas que siguen los modelos de sociedad imperantes. Bajo dicha razón, el narco-consumo se inserta también en lo comúnmente definido como globalización y las implicaciones que de ello se genere. Teniendo en cuanta este panorama preponderante en el discurso baumaniano. ${ }^{3}$

\footnotetext{
${ }^{3}$ Véase a Zygmunt Bauman, La globalización: sus consecuencias humanas (1999); Modernidad liquida (2004); Amor liquido (2005); Vida liquida (2006).
} 
Entre la riqueza y la extravagancia: El consumo excéntrico del narcotraficante en M éxico.

Por añadidura, las expectativas y los comportamientos relativos a los bienes costosos $<<$ ya no son lo que eran $>>$. Nuestra época ve desplegarse el $<<$ derecho $>>$ a las cosas superfluas para todos, el gusto generalizado por las grandes marcas, el auge de consumos ocasionales entre sectores más amplios de la población, una relación menos institucionalizada, más personalizada, más afectiva con los signos prestigiosos: el nuevo sistema celebra las nupcias entre el lujo y el individualismo liberal (Lipovetsky, Gilles, Roux Elyette, 2004)

La idea anterior sin duda puede explicar la realidad vivida en el fenómeno del consumo del narco contemporáneo. Que dicho sea de paso "en esta nueva época los narcos pasaron de ser negociantes rancheros a empresarios corporativos globalizados. Incorporaron a sus filas a especialistas en finanzas, telecomunicaciones, relaciones públicas, redes cibernéticas, espionaje, etcétera" (Santamaría, Brito y Martínez; 2009: 21).

\section{EL NARCO-CONSUMO ENTRE DOS DICOTOMÍAS: PASADO-PRESENTE Y RURAL-URBANO.}

A qué se le puede llamar narco-consumo, esa es la pregunta obligada. La perspectiva de la cual parte este trabajo es que hacer tal nombramiento a la práctica adquisitiva de un grupo determinado es solamente una manera analítica de identificar las características que han estado presentes en los consumos materiales y simbólicos hechos por los personajes (capos y líderes) de la droga en México a lo largo del tiempo. No es pues una definición conceptual en sí, sino una posible categoría de análisis que parte de una realidad presente, misma que le otorga una significancia. Con ello no quiere decir que tales acciones (narcoconsumos) se diferencien rotundamente de las demás formas de comportamiento adquisitivo respectivas a otro tipo de grupos o elites económicas existentes en el resto de la sociedad, sino que estas prácticas guardan algunas particularidades en las cuales la identidad y lo moderno -entiéndase como novedoso o de modaestán en un constante dialogo y reconfiguración.

El narco-consumo de los capos ha tenido variaciones a lo largo del tiempo. Es decir, no es posible hablar de una práctica homogénea en el transcurrir de las décadas. Han sido expresiones de un fenómeno sociocultural en el cual los 
elementos característicos de lo rural y lo urbano entran en una interacción constante en la que se reconfiguran los espacios y las significaciones. Por consiguiente, es posible hablar de dos formas tentativas por las que el narcoconsumo se ha expresado en México a través de los bienes materiales adquiridos por los narcotraficantes a los cuales se hace alusión.

Una de ellas, la tradicional, ha sido la circunscrita a un tiempo y estereotipo del narco mexicano, ya sea capo o perteneciente a los estratos inferiores de la organización, en la que el arraigo a la tierra y la identificación con la vida rural formó parte del sello distintivo en la práctica y forma de dicho consumo. Para este caso el llamado serreño conformó el modelo típico en cuestión de vestimenta y en los bienes materiales por ellos adquiridos.

Este modelo o estereotipo prefiguró como imagen estrechamente relacionada con la idea del gomero y lo que después serían los narcotraficantes sinaloenses que se contextualiza durante la cuarta y quinta década del siglo $\mathrm{XX}$, periodo en el cual Sinaloa presentaba marcadas particularidades expresadas en la dicotomía urbano-rural, es decir, un mundo cada vez más urbano con sus propias pautas de vida, donde los visos de apego a costumbres rurales no dejaron de estar presentes, en otras palabras, un mundo tradicional negado a morir ante el avasallante repunte de la modernidad y el progreso urbanístico desarrollado en la época.

Sin embargo, las labores de urbanización de un Culiacán que aún conservaba en esencia matices rurales no eran suficientes para darle el cambio necesario en cuanto a infraestructura se refiere. Ante esto cabe agregar que la población aún manifestaba conductas derivadas de habitar y sentirse en un espacio completamente rural, de esta forma, la existencia entre las modificaciones de carácter urbano y las costumbres rurales de su población se mezclaron para ofrecerle a Culiacán y a Sinaloa marcadas particularidades, fue pues;

un mundo urbano que se procura presentar como moderno... donde se devela cómo el modelo urbanizador va imponiéndose a todo aquello que se relacione con el mundo rural, tal vez porque lo rural comienza a parecer cada vez más como una clara señal de tradición y atraso... una ciudad que intenta presentarse vestida con un ajuar de progreso y captada con los 
Entre la riqueza y la extravagancia: El consumo excéntrico del narcotraficante en M éxico.

instrumentos que esta misma modernidad le prodiga [donde] Naturaleza y edificaciones, áreas públicas y privadas van adquiriendo nuevas dimensiones sociales a partir de los parámetros que marca la evolución material y la condición social de los habitantes de Culiacán, lo que seguramente generó prácticas humanas diferentes (Ojeda Gastélum, 2007: 17).

Los intentos de urbanidad de la época no terminaron de transformar los patrones rurales de comportamiento y esto influyó también de manera significativa en el consumo de los narcotraficantes, puesto que junto a las grandes fortunas acumuladas y reflejadas en las lujosas mansiones construidas por los gomeros en Culiacán, amuebladas con elegantes maderas costosas, así también han persistido vestigios de las viejas viviendas campiranas, costumbres y gustos rurales, elementos de la vida cotidiana que han articulado las formas más sofisticadas de la cultura urbana con las tradiciones rurales más típicas.

De acuerdo a lo anterior, tenemos que narcotraficante de antaño en Sinaloa -por tomar como ejemplo el modelo difundido por lo general en México (perteneciente a la segunda mitad del siglo $\mathrm{XX}$ )- comúnmente consumía una vestimenta identificada con lo denominado como cultura de rancho, es decir, con características rurales: botas y cinto piteado, sombrero vaquero o texano y pantalón de mezclilla. Uno de los narcotraficantes más representativos de esta imagen rural fue Lamberto Quintero Páez, de quien se describe su perfil

Era un individuo bien parecido, de color blanco, tez sonrosada y ojos azules, siempre usaba sombrero de palma o tejana, encasquetado hasta las orejas. [...] Por su postura le habían puesto el apodo de El Bonito [...] desde joven tuvo la pasión por los caballos, que más acostumbraba montar cuando andaba de juerga y atrás, de obligación, la tambora toque y toque. La Banda del Carro Rojo, de los Hermanos Quintero, era una de sus preferidas (Figueroa Díaz, 1992: 111-112).

Años más tarde se manifestó la imagen de un narcotraficante que combinó paulatinamente la dicotomía urbano-rural, considerado como un consumidor ostentoso de camionetas costosas, poseedor de casas y terrenos tanto en la ciudad como en el pueblo al cual pertenecía o mantenía algún tipo de relación identitaria-afectiva; su vestimenta fueron camisas versase con pantalones de 
mezclilla, todo en colores combinados, con estampados y diseños llamativos; también figuraban en sus pertenencias los relojes de marcas exclusivas, lo mismo que ornamentas como cadenas, esclavas y anillos de oro con un grosor notable, joyería acompañada de crucifijos o santos con piedras brillantes con un alto valor económico y simbólico (Santamaría, Brito y Martínez; 2009: 193-206).

El narcotraficante mexicano que mantuvo rasgos de ruralidad entremezclados con lo urbano ha sido también representado en la música del corrido, dicho sea de paso siendo ésta una expresión musical entendida como un elemento cultural conformador de una imagen y de breves biografías o relatos de vida (Héau Lambert, 2007: 53). De vidas enaltecidas e inmortalizadas en las letras de las canciones producidas y consumidas en sociedades que comparten determinados sistemas de valores culturales propios a su tiempo y de su pasado. Melodías que reproducen las prácticas del consumo opulento de los jefes del negocio; composiciones que exaltan las historias de hazañas, virtudes humanas, experiencias de vida, el peligro y valentía, la muerte y el triunfo de aquellos referentes fallecidos y vivos de la industria del enervante: de los gallos sinaloenses (Simonett, 2007: 86).

\section{DE NARCOS, EXTRAVAGANCIAS Y OTRAS BREVES HISTORIAS.}

Hacia los años ochenta del siglo $X X$, el resurgimiento del narcotráfico en Sinaloa en su forma más urbana y globalizadora desbordó los límites locales para extenderse a otras regiones y estados de la República haciendo deslucir a narcotraficantes como Eleodoro Cásares, alias El Culichi o Manuel Salcido Auzeta, alias El Cochiloco, cuyo consumo no sería tan excéntrico, por no decir austero (Zavala, 2007: 69).

Un caso particular de tal austeridad fue Miguel Ángel Félix Gallardo, quien se desenvolvió públicamente como hombre de negocios y ganó prominencia en los círculos sociales y políticos sinaloenses; a éste capo se le cataloga como un narcotraficante hábil, sagaz, discreto, refinado e insólitamente austero, el cual se convirtió en un personaje de la vida social y económica importante del estado. La clave de su éxito fue su discreción, pues nunca hizo ostentación de sus riquezas. . 
Entre la riqueza y la extravagancia: El consumo excéntrico del narcotraficante en M éxico.

En otra de las descripciones que se hacen de este personaje, la periodista Elaine Shannon comenta que;

Se trata de un individuo "sombrío", "delgado" y "callado" "matón despiadado", desdoblado en "empresario de trayectoria rápida" alguien que disfrazaba sus bajos orígenes de clase detrás de una apariencia brillante. También es el "traficante de cocaína más grande de México y uno de los más grandes del Hemisferio Occidental, tan poderoso como los jefes de Medellín. Habría que precisar que solo con una diferencia de 950 a 2950 millones de dólares menos, según los cálculos de Forbes (1987) (Astorga, 2004: 71-72).

Félix Gallardo fue un capo radicalmente distinto a Rafael Caro Quintero y Ernesto Fonseca, alias Don Neto. Al primero se le describe como un hombre con cara de niño, precoz, sin embargo el más audaz del grupo, un empresario iletrado pero natural, alguien que viste como símil de cowboy y le atrae mostrar joyas de oro y diamantes alrededor de su cuello, dedos y muñecas; un sujeto que apenas empezaba a apreciar el whisky escoses. Por su parte Don Neto, ha sido descrito con un perfil duro y temerario, un sujeto primitivo, vinculado con la imagen del viejo bandido montañés (Astorga, 2004).

Por su parte, Caro Quintero llegó a Guadalajara junto con otros narcotraficantes sinaloenses tras la persecución de la Operación Cóndor concentrada en Sinaloa durante las postrimerías del sexenio de Luis Echeverría. A partir de ese momento Jalisco se transformó. Los mafiosos se instalaron en los fraccionamientos de La Calma, Residencial Victoria, Lomas del Valle y Colinas de San Javier. El primer negocio que adquirieron fue el Gran Hotel. Compraron restaurantes, discoteques y otros negocios. Ostentaron grandes cantidades de dinero; compraron autos de lujo para la época como Ford Galaxies y Gran Marquis. De inmediato se hicieron notar en la ciudad con sus camionetas estilo pick ups, por el uso de sus armas y su típica vestimenta: estilo vaquero con esclavas, collares y anillos de oro (Ortiz, 2011, p. 18-19).

Otro caso a destacar es el de la Familia Arellano Félix y el Cártel de Tijuana, quienes hacia 1990 eran catalogados por la prensa como criminales apuestos, multimillonarios y despiadados. Una cuarteta de hermanos que viste y 
habla bien. Andan con smoking y solo por su presentación dicen en California "se les abrían muchas puertas" (Zamarripa, 2011, p. 40-41)

Nativos de Culiacán iniciaron con el contrabando vendiendo vino, cigarros y camisetas estadounidenses que llevaban de Nogales a Culiacán. Años más tarde controlarían uno de los pasillos más importantes de droga a Estados Unidos: la frontera con San Diego, California. Los hermanos se instalaron en Tijuana a comienzos de los ochenta y lograron consolidar su fuerza a partir de las detenciones de Félix Gallardo y Caro Quintero. Por lo que;

Los Arellano son multimillonarios y cada mes mueven toneladas de cocaína sudamericana a través de la frontera. Son protegidos por escoltas y contratan policías, así como a jóvenes ricos y miembros de las pandillas de San Diego [...] entre sus inversiones destacan avances en negocios del transporte, la industria de la construcción y la promoción deportiva (Zamarripa, 2011, p. 40-41)

Una obra arquitectónica perteneciente al narco en Mazatlán, fue la discoteca Frankie Oh, misma que llevó en mote Narkie Oh, propiedad de Francisco Arellano Félix este inmueble valuado en cinco millones de dólares fue diseñado con una fachada de piedra, con un decorado extravagante donde se posaba una avioneta militar incrustada en su techo; construida en el interior con un enorme teatro de pisos a desnivel, cascadas artificiales y una gran pista rodeada de peceras.

Hoy en día el narco-consumo, principalmente de aquel capo posicionado en los altos peldaños de la estructura del enervante, ha rebasado las propias fronteras históricas culturales a las que comúnmente se les han asociado. Si bien es posible hablar de una cultura del narco, o en otras palabras, una narcocultura, el consumo de los bienes y simbologías es parte también de dicho fenómeno económico y sociocultural (Córdova, 2011: 41). Elemento que se ve representado a través de la narco-extravagancia presente también en otras latitudes como lo ha sido el caso de los capos de las drogas de la tierra del café y el vallenato (Escamilla, 2002).

El capo consume una cantidad de bienes materiales con valores que en algunos casos se encuentran fuera de un simple posible cálculo en el mercado 
Entre la riqueza y la extravagancia: El consumo excéntrico del narcotraficante en M éxico.

local, convirtiéndose esto evidentemente en un hecho que lo distingue de sus pasados. El narcotraficante pesado-como se le denomina popularmente al líder o jefe de la organización del enervante en México- tiene el recurso económico suficiente como para llevar una vida de excentricidades y lujos, esto quizás porque como comúnmente se dice: el tiempo de vida de un narco es corto. Bajo esta tónica, en el consumo se encuentran mujeres bellas como el caso de la culiacanense Laura Zúñiga (Miss Sinaloa), o la modelo cafetera Angie Sanclemente (Miss Colombia), inclusive otras más como se relata en la obra Miss Narco. Belleza, poder y violencia: Historias reales de mujeres en el narcotráfico mexicano de Valdez Cárdenas (2009), han sido parte de las posesiones de los altos actores del negocio de las drogas en Latinoamérica.

A este narco-consumo se le suman las fiestas con lujos exorbitantes donde se presume han armonizado agrupaciones y cantantes de diversos géneros portadores de reconocida fama no sólo local y regional, sino nacional e internacional. Por otra parte, algo más de carácter material han sido las residencias y mansiones calculadas en varios millones de pesos o dólares -según sea el caso-, con acabados en interiores personalizados como las pertenecientes a los artistas y empresarios de Hollywood, a los líderes petroleros rusos y árabes, o algunos políticos mexicanos.

Uno de los bienes residenciales que hasta hoy en día han sido más recordados en México fue el incautado en el ocaso del año 2008 en un operativo realizado en el Desierto de los Leones, recinto que no sólo tuvo la particularidad de estar construido con una decoración hindú, sino quizás lo más insólito y pocas veces visto, salvo el caso del colombiano Pablo Escobar en la década de los noventas, fue que había dentro de la propiedad "un zoológico con dos leones africanos, un tigre blanco, uno albino, dos panteras y un chimpancé; y en un estanque había figuras de dos cocodrilos y un hipopótamo, en fibra de vidrio" (González, 2008).

Se le suma también a este tipo de consumo excéntrico la tecnología de punta en aparatos electrónicos de todo tipo, equipos de seguridad, avionetas, autos deportivos, joyas, obras de arte y reliquias históricas. Dicha práctica de 
consumo ha llamado la atención internacionalmente por las peculiaridades que llegan a presentar. Una muestra de ello fue el trabajo de Mariana Van Zeller, corresponsal del canal televisivo National Geographic, quien en el año 2012 realizó un documental titulado El lujo de los narcos. Otro trabajo fílmico con tinte periodístico ha sido el publicado por Natalia Almada, el cual lleva el titulado de El (Almada, 2011) documental en el cual se muestran los espacios para el eterno descanso poseedores de múltiples lujos como el caso de los mausoleos ubicados en el cementerio Los Jardines de Humaya, en Culiacán, Sinaloa; un panteón que se distingue por ser el lugar donde reposan los cuerpos sepultados de algunos líderes del narcotráfico sinaloense, a los cuales se les depositan en espacios construidos con materiales económicamente de alto valor acompañados con diseños arquitectónicos fuera de lo común.

Parte de las pertenencias de los narcotraficantes mexicanos resulta ser en ocasiones un secreto a voces. Es decir, estas son conocidas o sólo salen a la luz pública cuando son incautadas directamente a sus dueños en operativos realizados por las corporaciones policiacas y militares del Estado mexicano, o bien de forma indirecta cuando se confiscan bienes e inmuebles pertenecientes a dichos enemigos oficiales de la ley, como el caso de artículos y propiedades a los cuales se les subastan a través de eventos públicos oficiales organizados por parte del Servicio de Administración y Enajenación de Bienes (SAE) del Gobierno Federal.

Un ejemplo recientemente de ello se suscitó con la aprensión de José Eduardo Costilla Sánchez, alias El Coss, en septiembre de 2012, esto en un operativo de la Secretaría de Marina Armada de México. En dicha aprensión, de acuerdo con la versión oficial publicada en medios nacionales impresos, al presunto líder del cártel del Golfo se le decomisaron una serie de relojes y armas de fuego bañadas en oro, y poseedoras estas además de incrustaciones de diamantes. Lo particular del caso no lo representaron ser las armas, sino los relojes. Pero estos no por las prestigiadas marcas, sino más bien por la exclusividad de los mismos modelos como lo fue el Suiza Romaín Jarone, 
Entre la riqueza y la extravagancia: El consumo excéntrico del narcotraficante en M éxico.

diseñado -de acuerdo a la información difundida en los medios- con restos materiales del histórico barco Titanic (Vega, 2012).

En cuanto al tema de las armas de fuego, dentro de los decomisos hechos a distintas bandas de narcotraficantes, se encuentran armamentos hoy en día equiparables a los usados por el Ejército Mexicano, algunos de los cuales se introdujeron al país desde los Estados Unidos en lo denominado como operación Fast and Furious, acreditada al gobierno estadounidense. Estas armas cada vez más sofisticadas y con calibres más grandes cohabitan en el mundo del narco junto con escuadras pequeñas -más no menos efectivas- y las tradicionales e icónicas de los narcocorridos llamadas cuerno de chivo o Ak-47. Empero, a pesar de que la gran mayoría de las armas en el mundo del narco cumplen la función para ellas creada, otra parte de las mismas acompañan a los grandes capos como objetos de lujo con un alto valor económico y simbólico. La personalización de los fusiles ha sido un rasgo distintivo del narcotraficante mexicano.

Bañadas en oro y con incrustaciones de diamantes, adornadas con decoraciones hechas de forma manual referentes a las marcas Versace, Ferrari; santos, personajes de la Revolución Mexicana, frases inmortales de hombres íconos de la historia, nombres de sus dueños o el alias; águilas, halcones, gallos, serpientes y hojas de marihuana, son sólo algunos de los diseños -considerados para algunos como trabajos artesanales- encontrados dentro de esas armas acompañantes y a su vez manifestantes identitarios de los jefes del narcotráfico.

Evidentemente la cantidad y variedad de bienes conocidos que han sido posesiones de los narcos de los altos mandos rebasa la serie de artículos a los que hemos hecho mención en este trabajo. La lista es amplia y quizás puede escapar de toda imaginación. El lujo, la extravagancia y la excentricidad suelen estar marcadas por la sociedad, la cultura y contexto de cada época. Hoy en día dichas manifestaciones están presentes en mayor medida en lo material como resultan ser los bienes raíces o propiedades inmobiliarias, los medios de transporte como los carros deportivos y las camionetas Hummers como lo llegaron a ser en Culiacán durante una época reciente. 
Algunos otros elementos que vienen a engrosar la diversidad de bienes suntuarios son la vestimenta costosa y de difícil acceso incluso dentro de los comercios locales. En otro plano adscribimos a las armas como otro elemento importante, estas últimas personalizadas con tal detalle que han llegado a parecer más joyas o artículos de gran valor en oro y pedrería que armas de fuego. Son dichas expresiones las reliquias de la corona, las prácticas de consumo que distinguen a los unos de los otros. Es la demostración de opulencia y poder materializada y calculada en miles de dólares. Esto es algo que sin lugar a dudas los distingue del resto de los consumidores del común, pero a su vez también los unifica en lo que respecta al consumo practicado.

\section{CONSIDERACIONES FINALES.}

El narco-consumo al cual hemos hecho alusión, sin duda ha impactado en el resto de la sociedad. Un ejemplo de ello es lo llamado narco-moda. No igual a la extravagancia, al excentricismo e incluso al lujo exclusivo que llevan a cabo los grandes capos, la narco-moda con el paso del tiempo ha venido gestándose como una expresión cultural del narcotráfico en México y resto de Latinoamérica. Fenómeno que se manifiesta en los integrantes de las organizaciones del enervante y también fuera de ellas. Esta manifestación de la particular cultura que envuelve al narcotráfico consiste en la emulación o imitación de algunas prácticas de consumo e incluso de conducta estereotipadas con el narcotraficante, pero puestas en juego no sólo por éstos, sino por parte de la sociedad comúnmente receptora de diversos tipos de tendencias de consumo.

La narco-moda contemporánea adoptada para el caso de la vestimenta y ornamentos, comúnmente tiene como modelos marcas de ropa, estilos de la misma y hasta los usos que se le dan a ciertos aditamentos utilizados por los iconos del narco. En comparación con décadas anteriores, la imagen del narco hoy por hoy rompe con los estereotipos tradicionales en cuestión de vestimenta. Cada vez más las marcas de ropa estadounidenses e incluso europeas en boga en el mercado internacional son utilizadas por estos. Un ejemplo de ello se ha 
Entre la riqueza y la extravagancia: El consumo excéntrico del narcotraficante en M éxico.

evidenciado cuando algunos capos en México han sido capturados y presentados ante la justicia vestidos por lo común con camisetas tipo Polo marca Ralph Lauren.

Así como estos personajes del enervante portan y lucen a la luz pública sus gustos por ciertas marcas y modas referentes a nivel mundial, a su vez imponen modas; y más que obedeciendo a un determinismo económico, dicho fenómeno corresponde en mayor medida a una razón cultural, donde el valor monetario de la prenda o producto queda en un segundo plano. En ese sentido, la simbología atiende a un valor no material que juega un papel preponderante para quienes lo adoptan, emulan o imitan. Elementos que llegan a la sociedad receptora transmitidos por los mass media que reproducen este tipo de estereotipos a través de la información de diarios, videos musicales, películas y series de televisión que han tomado como eje central el tema del narcotráfico.

Este tipo de moda, ya sea adscrita al denominativo de subcultura e inclusive contracultura, ha sido adoptada por diversos sectores sociales sin distinto de sexo y ha llegado a convertirse en una problemática social en la medida en que para el gobierno ello representa una apología al narcotráfico, a sus principales referentes, y una forma de incitar a las conductas lejanas a la moral y fuera de lo normativo. Un ejemplo de las iniciativas para contrarrestar el auge de dichos gustos y prácticas de estos consumos fue la de prohibir los narco-corridos en bares, cantinas, centros nocturnos y salones de fiestas en Sinaloa en el año 2011. Sin embargo esta medida fue disuelta en el año 2013 por la Suprema Corte de Justicia de la Nación (SCJN) debido a una serie de inconsistencias legislativas.

Un caso atípico sobre las iniciativas del gobierno por erradicar la narcomoda se presentó en el mismo año 2011 cuando el actual Gobernador del Estado, en un evento público con motivo del Día del Niño en Los Mochis, Sinaloa, ofreció a un infante una bicicleta y mil pesos a cambio de que se quitara una camiseta estilo Polo similar a la llevada por Edgar Valdez Villareal, alias La Barbie, cuando fue presentado ante las autoridades del Estado durante ese mismo año. Una crónica de tal acto se encuentra en los medios de dicha localidad donde se narra que:

Antes de su intervención ante el micrófono, López Valdez observó al pequeño Luis Manuel que se encontraba entre la multitud y quien 
sobresalía por su vestir una playera London, invitándolo a que subiera al estrado, donde le hizo la tentativa oferta de compra. De su billetera sacó cinco billetes de 200 pesos y acercó la bicicleta que entregó al niño, quien a cambio de la playera de La Barbie se llevó también una de las camisetas de la campaña Ahome Despierta. Dejando a lado la fiesta, López Valdez convirtió su discurso en un llamado a los niños y los padres a velar por su cuidado y evitar caer en las tentaciones del crimen organizado. Aún más, de acuerdo a la invitación previa, todos los niños que llegaron con pistolas de juguete recibían a cambio balones deportivos (Cote, 2011).

Evidentemente el caso señalado en la nota anterior forma parte de una cultura en el plano de la vestimenta, enraizada y acrecentada en los últimos años particularmente en Sinaloa, en donde ahora más que nunca gran parte de la población consume este tipo de bienes por razones identitarias y mediáticas en la medida que buscan estar a tono con las tendencias consumistas llevadas a cabo por aquellos que directa e indirectamente imponen este tipo de modas en el ámbito local.

El narco-consumo y las excentricidades imperantes en dicha práctica en México, a pesar de ser parte de una visión tradicional del fenómeno representada a través de lo denominado como "el machismo estructural del narcomundo", no es un determinante de género, es decir, en el caso de la narco-mujer o las Jefas del narco, como lo titularía una obra sobre el tema, también están inmersas en el consumo material y simbólico de aquello lujoso y ostentoso dotándolo incluso con rasgos femeninos (Ovalle y Giacomello; 2008: 31).

Los estudios académicos y periodísticos del fenómeno del narcotráfico en México concuerdan en que dicha práctica de consumo es una forma cultural de expresión de estatus y poder por parte del narcotraficante (hombre y mujer) hacia el exterior e interior, es decir, una demostración de opulencia y autoridad hacia la sociedad que los rodea, asimismo a sus similares de peldaños más bajos y de otras organizaciones delictivas.

Sin embargo, esta idea de búsqueda -por parte del narcotraficante- de una representación material además de simbólica del estatus y poder no brinda una respuesta del todo sobre dicho excentricismo en el narco-consumo. Si bien el narco de hoy es un ser cada vez más globalizado y tecnológico, orillado por las 
Entre la riqueza y la extravagancia: El consumo excéntrico del narcotraficante en M éxico.

propias dinámicas del negocio imperantes actualmente, algo que lo ha distinguido de sus antepasados dedicados al negocio de la hierba mala, es quizá el elemento de distinción e identidad que lo ha llevado a la práctica del consumo excéntrico.

En pleno siglo XXI no sólo los patrones culturales del american way of life y de apariencia (modas en el vestir) estadounidenses se adoptan y reproducen en México, sino también los de la narco-cultura. Estilos de vida, de conducta y de vestimenta son parte de este fenómeno sociocultural. Marcas de ropa, formas de vestir, de comportarse, de vivir, de usar un automóvil o camioneta, de escuchar cierto tipo de música, todos estos elementos que han sido ligados y tomados como referentes icónicos. Es una narco-cultura adoptada e imitada por cierta parte de la población asidua a las modas de los llamados buchones (Alvarado Vázquez, 2012: 96-97).

La comercialización de la ropa estilo buchón -ésta una denominación de narcotraficante en Sinaloa- como la encontrada en los aparadores de la Plaza Fórum, en Culiacán, o vista a través de los videos musicales en los canales televisivos, ha transformado esa idea de la exclusividad e identificación presentada antes sólo en aquellos capos del narcotráfico. El portar una prenda de alguna prestigiada marca, el usar reloj y joyas de alto valor, el conducir un automóvil costoso con el sistema de sonido con altos decibeles reproduciendo un narcocorrido ya no representa más un lujo exclusivo para aquellos capos de una vida corta. En ese sentido, la divulgación devalúa. Por lo que en consecuencia: "la rareza del producto y la rareza del consumidor disminuyen en forma paralela" (Bourdieu, 1990:189).

\section{REFERENCIAS BIBLIOGRAFICAS}

Almada, Natalia. (2011) Documental, El Velador, extraído de https://www.youtube.com/watch?v=UbyoG9xAr7g consulta: 06/06/2018.

Alvarado Vázquez, Ismael. (2012) Imágenes rurales en la ciudad: Ios buchones, en Arenas. Revista Sinaloense de Ciencias Sociales, núm. 30, UAS, México (Pp.18-32).

Astorga, Luis (2004) Mitología de un narcotraficante en México. Plaza y Valdés. México.

Bourdieu, Pierre (1979) La distinción. Criterios y bases sociales del gusto. Taurus. España. 
Bourdieu, Pierre, (1990) Sociología y cultura. Grijalbo. México.

Cote, Gabriel (2011).Cambia mil pesos gobernador por camiseta, publicado en el Periódico Noroeste, extraído de http://www.noroeste.com. mx/publicaciones.php?id=683106\&id seccion=. consulta: 18/09/2012.

Córdova, Nery (2011) La Narcocultura: simbología de la transgresión, el poder y la muerte. Sinaloa y la "leyenda negra". Universidad Autónoma de Sinaloa, México.

Escamilla, Oscar (2002) Narco extravagancia: Historias insólitas del narcotráfico. Aguilar, México.

Figueroa Díaz José María (1992) La muerte de Lamberto Quintero. México, El Diario de Sinaloa, segunda Edición, México.

González, María (2008). Presume Siedo golpe a narcos, publicado en el Universal, extraído de www.eluniversal.com.mx/primera/31831.html consulta: 02/09/2012.

Héau Lambert, Catherine, (2007) El narcocorrido como mini-relato de vida, en Arenas. Revista Sinaloense de Ciencias Sociales, núm. 12, UAS, México. (Pp. 45-48).

Hobsbawm, Eric (2004) Historia del siglo XX. Crítica. España

Jaramillo, Fernando, (1996) Consumo ostentoso, crecimiento y distribución de ingreso, en Revista Desarrollo y Sociedad, núm., 36-37, Universidad de los Andes, Colombia (Pp. 56-72).

Lipovetsky, Gilles, Roux Elyette. (2004) El lujo eterno. De la era de lo sagrado al tiempo de las marcas. Anagrama. España.

Ojeda Gastélum, Samuel (2007) Culiacán. Gobierno de la República/Gobierno del Estado de Sinaloa/Ayuntamiento de Culiacán, Mexico.

Ortiz Pinchetti Francisco (2011) El hombre más buscado del mundo, en Los Rostros del Narco, Proceso, Edición Especial número 32, primera parte, año 34, Febrero. México (Pp. 18-19)

Ovalle Paola, Giacomello, Corina, (2008) La mujer y el narcomundo: imágenes tradicionales y alternativas, en Arenas. Revista Sinaloense de Ciencias Sociales, núm. 17, UAS, México (Pp.45-59).

Santamaría, Arturo, Brito, Pedro, Martínez, Luis A., (2009) Morir en Sinaloa. Violencia, narco y cultura. Universidad Autónoma de Sinaloa. México.

Simonett, Helena (2007) Los gallos sinaloenses y la música popular, en Arenas. Revista Sinaloense de Ciencias Sociales, núm. 12, UAS, México (pp.1925).

Simmel, Georg (1986) Sociología. Estudios sobre las formas de socialización, vol. II, Alianza Editorial. España

Valdez Cárdenas Javier (2009) Miss Narco. Belleza, poder y violencia: Historias reales de mujeres en el narcotráfico mexicano. Aguilar. México.

Veblen, Thorstein (1944) Teoría de la clase ociosa. FCE. México. 
Entre la riqueza y la extravagancia: El consumo excéntrico del narcotraficante en M éxico.

Wünderich, Volker (2002). Reflexiones críticas sobre el contexto global de la sociedad de consumo y la historia del consumo, en Revista de Historia, núm., 46., Universidad de Costa Rica, Costa Rica (Pp. 45-47).

Zavala, Arturo, Cultura y violencia en Sinaloa (2007) Historia, Moldes y Mitos. Ayuntamiento de Culiacán/Instituto Municipal de la Cultura. Mexico.

Zamarripa Roberto (2011) Apuestos ricos y despiadados en Los Rostros del Narco, Proceso, Edición Especial número 32, primera parte, año 34, Febrero. México. (Pp. 41-42)

Vega, Aurora (2012) El Coss fue detenido entre objetos lujosos, extraido de http://www.excelsior.com.mx/node/859035 consulta: 14/06/2018 